\title{
Community Mobility and Transport Use of Urban Older Adults Who Attend Public Healthcare in Gauteng, South Africa
}

\author{
*Hester M. van Biljon. B Occ Ther (UFS), M Occ Ther (UFS) PhD (Wits). \\ https://orcid.org/0000-0003-4433-6457 \\ Post-Doctoral Fellow. Stellenbosch University, Faculty of Medicine and Health Sciences, Department of Health and Rehabilitation \\ Sciences, Division Occupational Therapy, Cape Town and Private Practitioner, Work-Link Vocational Rehabilitation Practice, \\ Johannesburg, South Africa.
}

\author{
Lana van Niekerk. B Occ Ther (UFS); M Occ Ther (UFS); PhD (UCT). \\ https://orcid.org/0000-0003-0003-6006 \\ Associate Professor and Post-doctoral Fellowship Host, Faculty of Medicine and Health Sciences, Department of Health and \\ Rehabilitation Sciences, Division Occupational Therapy Stellenbosch University, Cape Town, South Africa.
}

Introduction: Older adults with limited socio-economic means, living in South Africa's most densely populated province, Gauteng, have experienced historical restriction and challenges to their freedom of movement. Interviews were conducted with older adults attending public healthcare facilities that offered rehabilitation service in Gauteng, to capture their community mobility experience and the modes of transport they used. These interviews explored the difficulties the older adults experienced and the strategies they employed to overcome them, with an invitation for them to give suggestions for improvement.

Method: An exploratory concurrent mixed methods study design saw 84 rehabilitation clinicians interview 393 older adults who visited public healthcare facilities where the clinicians practiced. The clinicians kept 109 field notes and took part in a cumulative five hours of group discussion. Quantitative data were analysed using descriptive statistics and qualitative data through inductive content analysis. Results: Walking and mini-bus taxis were the most prominent forms of community mobility. Fiscal and transport poverty, crime and poor infrastructure were barriers participants experienced. Community involvement and leadership accountability were suggested solutions. Conclusion: The community mobility and transport use realities of older adults, and the rehabilitation professionals who interviewed them, as well as strategies and suggestions to overcome the barriers they experienced should be noted by policy makers and service providers. Strategies are proposed to stimulate further consideration and development.

Keywords: transport poverty, limited socio-economic means, community involvement, leadership accountability, stake holders, Ubuntu.

\section{INTRODUCTION}

In his 2019 State of the Nation Address, President Cyril Ramaphosa' reminded South Africans that building a better South Africa was a collective responsibility. He urged a focus of efforts to eradicate poverty and reduce inequality. In 2018, when this study was done, the South African non-contributory social grant for persons 60 years and older, was R I 620.00 a month $^{2}$. Income constraint is linked to limitations in access to private and public transportation ${ }^{3}$, and historical policies of spatial segregation affect urban planning, creating urban sprawl $\left.\right|^{4}$ with low income groups located at the edge of cities ${ }^{5}$. Gauteng is South Africa's most urbanised province, accommodating $25 \%$ of the population; it also is home to the highest percentage $(24 \%)$ of adults 60 years and older ${ }^{6}$. Gauteng was the location for the study reported herein.

There have been calls for policy makers to address the safety and affordability of public transport for Africa's older adults ${ }^{7}$, and to apply universal design principles that will address the accessibility of South Africa's public transport ${ }^{8}$. Availability and accessibility have been identified as Gauteng's most pressing public transport problems ${ }^{9}$. The minibus-taxi industry, which operates on a for-profit basis, has been specifically noted as an obstacle for persons with special needs, as providing transport to them is not considered lucrative ${ }^{10}$, The same applies to older adults, as special needs are commonly linked to aging ${ }^{\prime \prime}$. South Africa has laws ${ }^{12}$ and policies ${ }^{13}$ that support international goals of universal access ${ }^{14}$ and the sustainability thereof ${ }^{15}$. In Gauteng, there are such initiatives ${ }^{4}$, but these focus on education and labour market commuters ${ }^{16}$. Further challenges are political inertia ${ }^{17}$, resistance to the implementation of universal design principles ${ }^{18}$ and that South Africa's urban areas lack the density and connectivity to support effective public transportation systems ${ }^{4}$.

In Ghana ${ }^{19}$, urban development was found to be most effective if shaped by communities and engagement with informal institutions and stakeholders, in contrast to the formal electoral paradigms that dominate urban development. A literature review ${ }^{20}$ on older people's mobility and transport needs in sub-Saharan Africa identified the importance of contributions by family and community members. Behrens and Gorgens ${ }^{21}$ proposed the introduction of complementary initiatives and wider stakeholder involvement to address transport problems in South African cities. The National Taxi Lekgotla ${ }^{22}$ is one such an initiative, however, it is concerning that older-adult- 
commuter-needs have not been considered at these lekgotlas.

The aim of this study was to capture the community mobility experiences of older adults with limited resources in Gauteng with reference to the modes of transport they used, the difficulties they experienced, strategies they employed and their suggestions for improvement. This article will focus on the following questions: a) What are the characteristics of adults aged $65+$ who attend public healthcare facilities where there are rehabilitation services, in Gauteng, South Africa, b) What are the community mobility and transport modes used by this group, and c) What were the restrictions they experienced and the strategies they employed to overcome them.

\section{METHOD}

\section{Research Design}

An exploratory concurrent mixed methods study design was used. The qualitative component, which used an exploratory descriptive approach, was complemented by quantitative findings.

\section{The Research Team}

The research team included the corresponding author, a postdoctoral fellow, and her host, the second author. Between March and May 2018, all rehabilitation clinicians working in public healthcare in Gauteng Province's Department of Health $(\mathrm{N}=193)$ were invited to participate in the study. They were contacted electronically, after which additional awareness of the research was created through presentations at various public healthcare meetings and forums. A multi-professional group of I 25 clinicians volunteered to take part in the study and were trained and equipped. Of these, $67 \%(n=84)$ complied with all aspects of the project by conducting interviews, keeping field notes, and taking part in debriefing and discussion groups. The 84 clinicians comprised 45 occupational therapists, - assistants and - technicians, 25 physiotherapists and - assistants, II speech and hearing therapists and audiologists and three podiatrists.

Training of the clinicians took the form of workshops held at their places of work. They received research kits that contained everything they would need to capture the data, such as interview forms and stationery. The clinicians were orientated in terms of the ethical and methodological principles of the research and familiarised with the interview form. The training included a review of the principles and practice of interviewing, keeping of field notes, professional reflection, debriefing and taking part in audiotaped group discussions.

\section{Participant Selection}

In total, 393 adults over the age of 65 consented to be interviewed for the study. Convenience sampling was use. The decision to recruit older adults at public healthcare facilities that offered rehabilitation services was based on the strategic location of these venues in urban areas, townships, and informal settlements, thus offering good access to the research population. The 84 rehabilitation clinicians approached potential older adult participants face-to-face when they attended the public healthcare facility of their choice. Inclusion criteria were community dwelling adults over the age of 65 , living in low resource urban communities in Gauteng and who utilised public healthcare facilities that had rehabilitation services. Each clinician was requested to recruit as many participants as possible. Interviews per clinician ranged from one to 12 , with a median of five interviews.

\section{Research Setting}

Data collection took place at eight public healthcare facilities in
Gauteng, where rehabilitation professionals worked. Older adults were recruited and interviewed on the same day that they visited these facilities for their healthcare needs. There was one interview conducted per older adult that took place in the rehabilitation treatment areas.

\section{Data Collection}

Using the researchers' experience of older adults with limited income, a 27-item semi-structured interview guide with open- and closed questions, was specifically designed for the research population. The first author conducted a pilot study of the interview guide in February 2018, after which changes were made to improve face and content validity. Interviews took place between I June and I4 September 2018. The first part of the interview captured biographical information, the second part explored meaningful out-of-home activities and places and the third part of the interview captured information on participants' community mobility and the transport modes they used. Their personal mobility and any use of mobility aids were explored. The modes of transport they used, length of journeys, frequency with which they used the modes of transport, accessibility and universal design issues were explored, as well as the difficulties experienced, strategies they employed to overcome them, and their suggestions for what would improve their experiences.

The interview guides were paper-based as clinicians did not have equal access to electronic devices. They were designed so an interviewing clinician could capture the older adult's responses in writing on the interview form and record field notes after each interview was done. The first author supported and encouraged the interviewing clinicians throughout the process of data collection. To maintain the confidentiality of older adults and clinicians' contributions, no identifiable information was captured. There was no remuneration or incurred costs for the older adults as the interviewing took place at the healthcare facilities they visited for healthcare needs and/or rehabilitation services. Concluding the data collection stage, the first author held debriefing and audiotaped discussion groups at the clinicians' places of work during October and November 2018.

\section{Data Management and Analysis}

The interviews, field notes and transcribed audio recordings were captured in Microsoft Word. Close-ended questions were captured using the response options in the interview guide, and a coding tree was inductively developed for the open-ended questions. Quantitative data was captured on Microsoft Excel before uploading it to SPSS $X$. Analysis of quantitative data was limited to descriptive statistics. The qualitative data were imported into WeftQDA for inductive content analysis. There are several ways to approach analysis and integration of the different types of data in mixed-methods research; in this study a fully integrated approach was used ${ }^{23}$. The integration of the qualitative and quantitative data occurred at the data collection, data analysis, and interpretation stages. Data analysis and interpretation were done in a cyclical process with researchers moving back and forth between the different findings to reach consensus on the key findings.

\section{Trustworthiness and Rigor}

A pilot study was used to improve the face and content validity. Internal validity was addressed by capturing and using a variety of data sources and inter-rater reliability by providing the same training on data collection techniques to all participating clinicians. Both authors received the raw data for individual analysis and the final synthesis of the data was by mutual agreement. 
Table I: Demographics of older adult participants $(\mathbf{N}=393)$.

\begin{tabular}{|c|c|}
\hline $\begin{array}{l}\text { Mean age: } \\
72 \text { years (range } 65-98)\end{array}$ & $\begin{array}{l}\text { Gender distribution: } \\
\text { Female } 73 \%(n=287) \text { and Male } 27 \%(n=106)\end{array}$ \\
\hline \multicolumn{2}{|c|}{$\begin{array}{l}\text { Language proficiency: } \\
87 \%(n=342) \text { of participants were bilingual and } 60 \%(n=236) \text { multilingual. English }(n=252) \text { was the most spoken, followed by Zulu }(n=196) \\
\text { and Afrikaans }(n=196) \text {. Most SA official languages were recorded to be spoken, as well as other African languages and Portuguese. }\end{array}$} \\
\hline $\begin{array}{l}\text { Education level: } \\
\text { No formal schooling II\% }(n=39) \\
\text { Primary School } \quad 41 \%(n=161) \\
\text { High School } \quad 41 \%(n=161) \\
\text { Tertiary } 7 \%(n=27)\end{array}$ & $\begin{array}{l}\text { Main source of income: } \\
\text { Pension } 93 \%(n=366) \\
\text { Salary } \quad 7 \%(n=26) \\
\text { Average number of dependants on an income was } 2 \text { (Range of dependants } \\
0-12)\end{array}$ \\
\hline $\begin{array}{l}\text { Type of abode: } \\
\text { Brick houses owned by participant or family member } 87 \% \\
(n=342) \text {, } \\
\text { Other forms of abode, e.g., old age home, flat or rented room } \\
13 \%(n=51)\end{array}$ & $\begin{array}{l}\text { Number Inhabitants: } \\
\text { Those who lived in their own or family's house shared it with an average of six } \\
\text { other occupants (Range was } 0-18 \text { ) }\end{array}$ \\
\hline $\begin{array}{l}\text { Access to amenities inside the home: } \\
\text { Water \& electricity inside the home } \\
93 \%(n=366) \\
\text { Electricity (no water) inside the home } \\
5 \%(n=20) \\
\text { No water or electricity inside the home } \\
2 \%(n=8)\end{array}$ & $\begin{array}{l}\text { Location of traditional family home/place of origin: } \\
\text { Gauteng } 66 \%(n=259) \text {, Outside of South Africa } 21 \%(n=83) \\
\text { Eastern Cape } 7 \%(n=26) \text {, North West } 6 \%(n=25)\end{array}$ \\
\hline
\end{tabular}

The uniqueness of South African settings, and the use of a convenience sample, limits external validity. However, the operationalisation of the research was deliberately kept simple and documented in the protocol, consent forms and various dissemination formats to improve reproducibility of the study.

\section{Ethical Considerations}

Rehabilitation clinicians who participated in the study received written and verbal information about the study, they were informed of their right to decline participation without consequences, and given the opportunity to ask questions, discuss and contemplate their participation; they gave written consent. Older adults who were approached by the clinicians to be interviewed for the study were given verbal information of the study, informed of their right to decline participation with no consequences to their right to healthcare services and supplied with an information sheet to take home. They gave verbal consent to be interviewed and no demographics that could lead to identification were captured.

The study was conducted in accordance with the World Medical Association Declaration of Helsinki under the auspices of Stellenbosch University and in collaboration with Gauteng Health. Stellenbosch University's Human Research Ethics Committee (HREC) provided ethical approval, Ref No: NI8/0I/003. Gauteng Healthcare's Research Committee approved the research, allowing the conducting within Gauteng Public Healthcare, Ref No: DRC Ref 2018-03-008. The South African National Health Research Database (NHRD) registered the study, Ref No: GP20I802 022

\section{RESULTS}

\section{Demographics}

The personal, domestic, and socio-economic demographics of the 393 interviewed older adults are presented in Table I (above).

\section{Mobility and Transport Modes}

Walking followed by minibus taxis were the most used forms of community mobility and transport modes reported. Private vehicles, buses, trains, tuk-tuks, planes and bicycles were also used. Discussed below are the reported experiences.

\section{Walking}

Walking was reported by $89 \%$ of older adults to be their main mode of mobilisation in the community and done daily. The mean duration for walking was 35 minutes (range 5 - 60 minutes). Older adults walked to friends and family in their neighbourhood, clinics and community centres, places of worship, *spaza shops , and transport pick up/drop off points. The most frequently reported reason for walking was "because I have to" [Interviews]. Walking was reportedly more frequent towards the end of the month when their funds were depleted and showed practical considerations:

"I walk to the shops but take the taxi when I come home because my shopping is too heavy." [Interview]

Older adults cited the exercise and health value of walking; a view reportedly promoted by rehabilitation clinicians who encouraged them to be active. Considerations for choosing not to walk and reverting to public or private transport were related to the distance that needed to be covered, cold and wet weather, the daylight factor and crime:

"I only walk in daylight times because if it is dark, it is trouble to be outside." [Interview]

Older adults' walking efficiency, their use of mobility aids and difficulties experienced are summarised in Table II (p37).

Clinicians highlighted poverty, as the predominant reason why older adults walked.

"They walk but not by choice - if only they had more choices. Money is the biggest issue when it comes to transport. Their pension is used for things such as groceries, so they walk to save money." [Discussion group] 
Table II: Factors Related to Walking Mobility $(\mathbf{N}=393)$.

Walking efficiency:

No problem - 49\%, Some problem -37\%, Extreme problem - I4\%

Mobility aids that were used: Bilateral and single elbow crutches $/ \mathrm{s}(\mathrm{n}=67)$,

Use of mobility aids for walking: Never use mobility aids $67 \%(n=262)$.

Use mobility aids (occasionally and all the time $)-33 \%(n=|3|)$

walking cane/stick $(n=36)$, wheelchair $(n=31)$, walker $(n=15)$

Note to reader: The reason why the total exceeds the $\mathrm{n}=|3|$ who reported using mobility is that in some cases different types of mobility aids were reported to be used by the same person.

Difficulties experienced and restrictions to walking:

- Fear of falling: This was related to personal mobility restrictions and poor road surfaces

- Crime: This was predominantly opportunistic snatch-and-run crimes.

"Just because I am old the nyaope** boys will come and take my phone."[Interview]

- Community unrest

"When my people are angry, we all stay at home" [Interview]

- Poor/lacking infrastructure: Poor or non-existent sidewalks, shelters, ramps, and public amenities.

"I cannot walk too far as there is no place to sit down and rest and there are no toilets along the way." [Interview]

- Problems related to mobility aids:

"If you walk with crutches, you cannot carry anything because your hands are holding something." [Interview]

- Unlawful and dangerous road user behaviour:

Motor vehicles did not honour pedestrian crossings.

[Discussion group]

"I must always be careful of fast cars" [Interview]

- Other:

"You know white people, they make their gardens on the sidewalks and leave us no place to walk, then we have to walk in the roads with the cars." [Interview]

This is in keeping with a study conducted in Los Angeles, America, where focus group discussions with low income older adults confirmed that walking dominates other travel modes ${ }^{24}$. They also noted challenges when doing so due to deteriorated built environments, heavy traffic and crime ${ }^{24}$. In this South African study, the impact of crime and community unrest differed depending on the area in which the older adults lived. In some areas, the community looked out for older adults living amongst them.

"They walk to their destinations; often these are long walks and often alone, but they do feel that the community here is safe. If something happens someone will most likely help them even if they do not know them.' [Discussion group]

Clinicians also noted the positive element of walking,

"She likes walking and finds it helps with the management of her pain." [Field note]

\section{Minibus Taxi}

The second most frequently used mode of transport was the minibus taxi. This is commonly a 10 to 14-seater used to operate an unscheduled transport service for reward, mostly to or from a taxi rank. The taxi industry consists of private non-subsided enterprises that make up $60 \%$ of public transportation in South Africa ${ }^{25}$. The reason reported for choosing to use mini-bus taxis was that they were the most readily available form of transport. The problems and benefits associated with using mini-bus taxis shown below reportedly intensified during peak hour times and/or when raining

- Driver and commuter behaviour. Drivers were reportedly impatient towards commuters who were slow or hard of hearing. Public scolding and humiliation were reported.

"They can shout at you woza woza gogo you are making us all late." [Interview]

Fellow commuters

also complained if there were delays

or inconveniences.

"Here in the cities young people have forgotten to respect their elders." [Interview].

Similar experiences were reported in a study conducted in India ${ }^{26}$, where older adult commuters frequently encountered a lack of concern and indifference, and expressed their frustration and indignation with such behaviour, especially from the younger generation, which led them to feel disrespected and uncared for. A participant from the Indian study reported being told: Everybody is in a hurry! Climb, climb, climb! Old man get in! Why are you troubling? Get in! 26:324.

- Danger. Older adults felt themselves to be in danger due to the poor roadworthiness of vehicles, reckless driving, and risk-taking behaviour of the taxi drivers. Furthermore, crime, such as pick-pocketing or snatch-and-run-incidents that took place in taxis and taxi ranks were prevalent. Another concern pertained the safety of drop-off points.

"They can stop in front of other cars and leave you to be running to cross the street with cars shouting at you." [Interview]

- Inaccessibility, congestion, and overcrowding. Space inside a taxi is confined, making it difficult to secure a seat, especially when the taxi is full, a problem that was compounded with the use of mobility aids. There were further problems reported associated with disembarking from the taxi.

"They stop and there are other people pushing past you to get out because you are slow"' [Interview]

The opening and closing of the sliding door posed problems for older adults who have reduced strength or problems with handgrip.

*A spaza shop is a small informal convenience shop business in South Africa, usually run from or near the owner's home, selling small everyday household items.

${ }^{* \star}$ Nyaope boys are youths addicted to cheap street drugs called nyaope. 
- Taxi Ranks. Both formal and informal taxi ranks require standing, often in queues, while waiting for a taxi. Taxi ranks were reportedly high-risk sites for falling, getting lost, misplacing personal belongings and exposure to criminal activity due to the jostling of commuters, lack of infrastructure and general disorder.

- Multiple transfers. Having to use several taxis, or modes of transport to reach a destination amplified the problems associated with this mode of transport.

"It confuses me, and I get so tired because it is in and out and in and out." [Interview]

- Taxi culture. To indicate one's desired destination to passing taxi drivers involves the use of hand signs. Deformity of the hands, poor eyesight or memory reportedly affected this ability. The seating position inside a taxi also require consideration because there are safety considerations and additional responsibilities associated with the seating. The front seat was considered a dangerous position. Furthermore, commuters in the front seat are required to assist the driver with receiving payment and giving change, which requires calculation under pressure and comes with the risk of having to compensate any shortfall in the fares. On the positive side, front seats offered more legroom and were easier for access/exit.

"I can only sit comfortably in the front because there is more space for my legs [she had arthritis in her knees], but it is a very dangerous place to sit because you will be the first one to die if there is an accident." [Interview]

- Benefits associated with using mini-bus taxis. Despite not having formalised routes or schedules, they are ever present and often the only available transport option. In some communities, taxi drivers took care of older adults.

"If you know the (taxi) driver he can look out for you. It is always the same one who picks me up when I go to the clinic, and he chases others away to make room for me in the seat at the door so I can get in and out easily." [Interview]

The main advantages of mini-bus taxis were reported to be that they operated routes that brought older adults close to their destinations and were a familiar mode of transport.

Clinicians highlighted accessibility problems and expressed dismay at reported public humiliation experiences, emphasising that this was particularly offensive within the African culture:

"An old person is everybody's grandmother even if you don't know her." [Discussion groups]

Clinicians told of incidents where taxi drivers charge a double fare if an assistive device was deemed to use up space, and that this was also the case for large persons who were considered to take up seating space for two people.

\section{Private Motor Vehicle}

Renting or hiring a private motor vehicle was the third most frequently reported mode of transport. When walking was not possible and public transport not available, private motor vehicles were hired or organised to take older adults to their destination. If the vehicle belonged to a family member, older persons were transported free of charge, or they would be expected to cover only the cost of fuel.

"My daughter has a car, and it is good for us to ask her to take us to the hospital when we had to see the big doctors (specialists)." [Interview]

If the vehicle belonged to a non-relative, there was usually a negotiated cost. Older adults also reported using commercial sedan taxis, such as Uber or other taxi franchises.

Many older adults in the study $(66 \%)$ had never driven or owned a motor vehicle. Of those who could drive, only I I\% were still driving. Reasons for driving cessation were predominantly socio-economic factors included inability to afford the cost vehicle upkeep and having given their vehicles away to their children. Four participants cited age and/or disability-related reasons for stopping driving. Clinicians highlighted that, older adults with disability (including wheelchairs users) generally had to rent a car to get around. There were also incidences of goodwill reported.

"My patient still drives, and he often provides lifts to people who live in his area." [Discussion group]

\section{Bus}

Only 15\% of older adults used buses and mostly only for long distance journeys outside Gauteng. Long distance bus services were operated by franchises, or as private rentals. They used these to go to religious festivals or visiting family homes in rural areas or neighbouring African countries. Only two adults used a bus daily and both were still working. They reported preferring to use the bus, as driver behaviour was better than in taxis, bus stops were in a better condition than taxi ranks, busses were more spacious, and the fee was fixed. Problems that affected the use of busses were accessibility. Bus stops were generally located far from home and physical access was reported to be a challenge.

"I struggle to get up the steps on the bus, they are too high.” [Interview]

Clinicians added that, busses operating in lower socio-economic areas were not adapted for special needs; it was difficult to get into a bus with walking aids and impossible to do so with wheelchairs.

\section{Train}

Gauteng has two passenger train options. A rapid transit railway (RTR) system funded by a public-private partnership with routes to the inner city and affluent areas, and a passenger train operated by a parastatal institution. None of the older adults reported having used the RTR system. The parastatal passenger train transport is more widespread and located in lower socio-economic areas. Only $3 \%$ of participants reported using the train, mostly on a yearly or monthly basis and for visiting family and traditional homes outside Gauteng. One participant used the train on a weekly basis to go to work and elaborated:

"Even as a young man I came to Egoli with the trains to work. I know it too well." [Interview]

Opinions on the use of trains varied. Reasons for choosing to use trains 
were reliability, affordability, comfort, safety, and familiarity with the transport mode. Problems reported included, that the stations were too far from homes, getting in and out of the trains was difficult, and overcrowding during peak travel times sparked a fear of falling and concerns of being robbed:

"You cannot always be sure to have a seat and when the train comes everyone is running and pushing." [Interview]

\section{Tuk-Tuk}

Tuk-Tuks are three-wheeled motorised rickshaws operated for reward. These were only available in two of Gauteng's five districts. Only $1 \%$ of participants reported using this mode of transport, usually on a weekly basis. Positive aspects were that Tuk-Tuks were cheap and personalised. Tuk-Tuk drivers were attentive and friendlier than mini-bus taxi drivers were and would pick you up or drop you off in front of your house. Problems with this mode of transport were accessibility, feeling exposed, as there were no doors, inconsistent availability, drivers drove too fast, and the integrity of their brakes were questioned. Passengers were also subject to intimidation tactics by mini-bus taxi drivers who saw Tuk-Tuks as competition.

"If you are in a Tuk-Tuk, the taxi drivers can give us too many scares and make you pray for your life." [Interview]

\section{Plane}

Three participants reported using a plane annually. The costs for these trips were covered by participants' children $(n=2)$ who worked abroad and for one, a retired domestic worker, by a previous employer. They reported extreme satisfaction with this mode of transport, describing it as a momentous experience.

\section{Bicycle}

Two participants, both male, used bicycles daily. Their average journey was 45 minutes, and both were satisfied with this mode of transport. They considered cycling to be an affordable transport mode that kept them healthy and allowed them freedom of movement. Problems experienced with cycling included exposure to crime, the absence of bicycle lanes and having to cycle on sidewalks or share roads with motor vehicles, and destinations not having shelters and bicycle racks. However, these problems were no worse than walking, which was their other option, and that they preferred cycling.

\section{Strategies, Recommendations and Suggestions}

Towards the end of the interview, older adults were given the opportunity to share strategies they used to overcome the barriers they experienced when leaving their homes. The interview forms show that older adults went beyond just sharing strategies, as several made recommendations and gave suggestions of what other people could do to address their mobility and transport challenges. Clinicians were also asked to make recommendations in this regard, and these were captured during group discussions and in their field notes.

Having an accompanying person was a prevailing strategy reported by older adults:

"You must never walk alone." [Interview].

Accompanying persons included children, grandchildren, spouses, and unemployed neighbours, however the latter needed to be remunerated. If using transport, an accompanying person accrued additional cost. The problem of inconveniencing someone was also reported:
"I need somebody to go with me but that somebody is not always wanting to go." [Interview]

Both older adults and clinicians highlighted the need for universal design compliance and recommended it for all forms of transport, except planes. The suggestion was to apply universal design principles to sidewalks, taxi ranks, bus stops, railways stations and vehicles. The need for convenient and accessible bus routes, public toilets, benches, bicycle lanes, mini-bus taxi drop-off and pick up points and a greater variety of transport modes was suggested.

In their field notes, clinicians suggested community and stakeholder awareness and involvement. There were discussions about national and local education and awareness campaigns during the group sessions, with a specific focus on the taxi industry; this involved local leadership accountability from community leaders, taxi owners and church leaders. It was felt that such leaders should introduce community discussions and that they should lead by example, demonstrating social norms and behaviour that value older adults. An older adult also alluded to greater community involvement with the suggestion:

"Rich people should pick us up when they drive past us with their cars." [Interview]

In the group sessions, the clinicians suggested the expansion and subsidising of designated transport for older adults to and from places of worship, shopping centres and healthcare facilities. One older adult participant gave a solution for the impact that limited financial means had on her community mobility

"Just give our children jobs then all will be right" [Interview].

\section{DISCUSSION}

\section{Demographics}

More than half of the older adults interviewed (66\%) were urbanised citizens who considered Gauteng their primary home. However, $44 \%$ reported the concept of also having a traditional family home, which was seen as the place where you were born and raised. This required the maintenance of rural-urban linkages and the need to commute between them. These findings were supported by Njwambe et al. ${ }^{27}$ who reported this aspect to be important for economic, socio-cultural and political reasons. The benefits of urban living could be the reason why the older adult participants' mean age of 72 years, was more than a decade higher than the 64 year life expectancy for South Africans ${ }^{6}$. Most of them lived in brick houses (87\%) that had water and electricity (93\%); in contrast to the rural reality described in a study by McAdam et $\mathrm{al}^{28}$ which showed how, especially for woman, the daily collection of water and fuelwood limited their occupational choices. Income sharing and the sharing of their homes with extended families are practices well reported ${ }^{29}$ in lower income South African societies. Participants in this study shared their homes with an average of six other persons. Most of them (93\%) were dependent on the noncontributory government old age pension, which was R I 700.00 in $2018^{30}$, when the interviews were held. This income was shared with an average of two family members and/or friends, which reflects the pan-African philosophical framework of Ubuntu ${ }^{31}$. The older adults' education levels reflect the legacy of the Bantu Education Act, which 
they would have experienced being of school-going age in the 1960's. Despite this, $87 \%$ were bi- and $60 \%$ multi-lingual.

\section{Mobility and Transport Modes}

The community mobility and transportation experiences of older adults in this study were not unique or recent, and found to be context specific. Different experiences of the same mode of transportation were reported from one community to another, which adds to the complexity of the issue and rules out blanket solutions. Community initiatives directed at addressing urban problems in Africa have shown to be effective ${ }^{32}$ and public transport policies need to involve a plurality of actors across different sectors ${ }^{33}$; which resonate with the Ubuntu philosophy, a prevailing pan-African strategy. Within the Ubuntu paradigm, an individual is perceived as part of a collective, where members of the community co-exist by collaborating with and looking out for each other ${ }^{31}$.

\section{Strategies, Recommendations and Suggestions}

When seeking to address challenges, a collaborative engagement approach with key stakeholders is required to address challenges in the exposition of existing strategies and the compilation of suggestions and recommendations from within the affected community. Once there has been an identification of the barriers, and strategies to address them postulated, assistance from outside the collective could be sought. This approach to addressing barriers is often complex, multi-faceted and time consuming. In addition, the inequality of South African society, would require the need to first foster knowledge, insight and understanding of each other's realties.

In this study, older adults reported using active travel to address challenges pertaining the availability and accessibility of transport, although cost was a significant factor. Active travel was not without challenges, and an additional strategy of being accompanied was applied. The latter extended beyond walking, to other modes of transport. There should be further exploration of active travel modes to gain greater insight into these and create evidence that will support and strengthen such initiatives.

Universal design, defined as the design and composition of an environment to optimise access, was called for in all modes of transport, except planes. The value of universal design has well-documented principles. However, application to community mobility and transport require community buy-in and political will. Within Gauteng, there are numerous examples, including the Gautrain, designated bicycle lanes and traffic lights, that accommodate hearing and visual impairment, but these are predominantly in the affluent areas of Gauteng's cities. Change is possible in interactive communities with strong leadership. This was seen in some of Gauteng's communities during the July 202 I unrest, when taxi owners and drivers congregated to protect shops and retail outlets in their communities against vandalism and looting.

Suggestions and recommendations made by participants included designated transport and addressing unemployment of older adults' children. These suggestions were not new; solutions such as the implementation of Basic Income Support ${ }^{34}$ has been debated for many years and reduction of unemployment remains on the country's agenda - in his 202I State of the Nation Address, President Ramaphosa again mentioned the creation of jobs as a priority ${ }^{35}$.

\section{CONCLUSION}

The presidential call for South Africans to take collective responsibility for their future and the wellbeing of all, resonates well within an African context. A community that takes ownership of its challenges, and the welfare of its older adults, will hold its leadership account- able and include older adults into the planning and management of community mobility and transportation. Within this gambit, older adults might need assistance to mobilise themselves, as has been the case with persons with disabilities. In South Africa, persons with disability already have a recognised status as consultants in matters that pertain to their community participation; the same should apply for older adults, because there should be no assumptions that the needs of these groups are the same.

\section{LIMITATIONS OF THE STUDY}

Clinicians reported difficulty fitting the interviews with older adults into their busy public healthcare practices. Language barriers could have affected the quality of interviewing as interviewers reported having to translate and explain abstract and open-ended questions. There were difficulties interviewing older adults with speech and/or hearing problems reported, with no mitigation registered, as only II of the clinicians had speech and hearing training to address this situation.

\section{AUTHOR CONTRIBUTIONS}

Hester van Biljon contributed to the conceptualisation of the research and was involved in all phases of design, operationalisation, data collection, analysis, data curation, writing of the first draft and revision of text to completion. Lana van Niekerk contributed to the conceptualisation of the research and provided supervision of all phases, analysis, data curation, writing, review \& editing.

\section{CONFLICT OF INTEREST DECLARATION.}

The authors declare they have no conflicting interests and no financial or personal relationship(s) that may have inappropriately influenced them during the research and/or in writing this article.

\section{FUNDING}

There was no funding or grants awarded for this study, the researchers self-funded all the costs.

\section{ACKNOWLEDGEMENTS}

The study stemmed from a project discussed by $\mathrm{I}-\mathrm{CHaT}$ (the International Expert Advisory Panel on Community Health and Transport) and saw a collaboration between Stellenbosch University and Gauteng Health. Indebtedness to and acknowledgement of rehabilitation clinicians' voluntary involvement, Gauteng Healthcare's rehabilitation management for their support and acquiescence, and all the older adults who consented to the interviews, Prof. Nicola Plastow for her help and support with the statistical analysis, Blair McDougall and Nurya van Biljon for assistance with data capturing and Luther Monareng for his advice and insights on urban township living.

\section{DATA AVAILABILITY}

All raw data are available from the corresponding author upon reasonable request.

\section{REFERENCES}

I. Ramaphosa C. 2019 State of the Nation Address (SoNA). Cape Town, 2019.

2. Nzamba T. What you need to know when applying for a SASSA grant. South Coast Herald, 29 August 2018, p. South Coast Sun.

3. Lucas K. Running on empty: Transport, social exclusion and environmental justice. Ist ed. Bristol, Great Britian: Policy Press, Imprint of Bristol University Press, 2004. https://www.scopus.com/inward/ record.uri?eid $=2-$ s2.0-84996524096\&doi $=10.1680 \% 2 F j$ tran. 15.00 
073\&partnerID =40\&md5 =9e6784a83bad92 Ib3eab |453b55dde52

4. McKay T. South Africa's Key Urban Transport Challenges. In: Massey R, Gunter A (eds). Switzerland: Urban Geogrpahy in South Africa. Springer, pp. 189-207.

5. Lucas K, Mattioli G, Verlinghieri E, et al. Transport poverty and its adverse social consequences. In: Proceedings of the Institution of Civil Engineers - Transport. Institute for Transport Studies, Faculty of Environment, University of Leeds, Leeds, United Kingdom: Thomas Telford Services Ltd, pp. 353-365.

6. Statistics South Africa. Mid-year population estimates 2018. 2018.

7. Olawole MO, Aloba O. Mobility characteristics of the elderly and their associated level of satisfaction with transport services in Osogbo, Southwestern Nigeria. Transp Policy 2014; 35: 105-1 16. https://doi.org/10.1016/j.tranpol.2014.05.018

8. Vanderschuren M, Phayane S. Mobility barriers for older persons and people with universal design needs in South Africa. In: Road Safety View project NMT in Africa View project, p. Conference on Mobility.

9. Vanderschuren $\mathrm{M}$, Cloete RO. The improvement of public transport operational performance: The case for Gauteng Province, South Africa. 25th Annu South African Transp Conf SATC 2006 - 2010 Will Transp Infrastruct Syst be Ready 2006; 2006: 130-140.

10. Lister HE, Dhunpath R. The taxi industry and transportation for people with disabilities: implications for universal access in a metropolitan municipality. Transform Crit Perspect South Africa 2016; 90: 28-48. http://doi.org/10.1353/trn.2016.0009

II. Szanton SL, Xue Q-L, Leff B, et al. Effect of a Biobehavioral Environmental Approach on Disability Among Low-Income Older Adults: A Randomized Clinical Trial. JAMA Intern Med 2019; 179: 204-21I. https://jamanetwork.com/journals/jamainternalmedicine/article-ab stract/2720I36\#: :text=2)\%3A204-2II.-,doi\%3Al0.100I/ jamainternmed.2018.6026,-editorial\%20comment\%20icon

12. South African Government. The Constitution of the Republic of South Africa. The Bill of Rights, Republic of South Africa:

https://www.gov.za/documents/constitution/chapter-2-bill-rights, 1996.

13. Government of South Africa. National Development Plan 2030. 201 I.

14. United Nations. World population ageing, 1950-2050. United Nations Publications, 2017.

15. United Nations. Sustainable Developmental Goals (SDG's) 2030. 2015.

16. Mamabolo A, Sebola M. Contemporary transportation systems in South Africa: a challenging consequence to min-ibus taxi industry. Bus Manag Rev 2018; 9: 2018. https://search.proquest.com/openview/a907f।7c 0d85a4f6cd0c74afd395 $\mathrm{fl}$ 68/ $\mathrm{I}$ ?pq-origsite $=$ gscholar\&cbl $=20266 \mathrm{I} 0$

17. Lucas K. Making the connections between transport disadvantage and the social exclusion of low income populations in the Tshwane Region of South Africa. J Transp Geogr 201 I; 19: 1320-1334. https://doi.org/10.1016/j.jtrangeo.2011.02.007

18. Thompson P. Challenges and Successes in the Application of Universal Access Principles in the Development of Bus Rapid Transport Sytems in South Africa. Stud Health Technol Inform 2016; 229: 629—638. http://europepmc.org/abstract/MED/27534360

19. Opoku-Agyemang K. Democracy in Ghana: Everyday Politics in Urban Africa. Routledge. Epub ahead of print 2 january 2019. https://doi.org/10.1080/00083968.2020.1720942.

20. Porter G, Tewodros A, Gorman M. Mobility, transport and older people's well-being in sub-Saharan Africa: Review and prospect. In: Geographies of Transport and Ageing. Department of Anthropology, Durham University, Durham, United Kingdom, pp. 75-100. https:// doi.org/10.1007/978-3-319-76360-6_4

21. Behrens R, Görgens T. Challenges in Achieving Universal Access to Transport Services in South African Cities. In: Watermeyer B,
McKenzie J, Swartz L (eds) The Palgrave Handbook of Disability and Citizenship in the Global South. Cham: Springer International Publishing, pp. 183-196.

https://doi.org/10.1007/978-3-319-74675-3_13

22. Mbalula F. National Taxi Lekgotla. Johannesburg, 2020.

23. Cresswell JW. Research Design: Qualitative, quantitative and mixed methods approaches. 3rd ed. SAGE Publications, 2013.

24. Loukaitou-Sideris A, Wachs M, Pinski M. Toward a Richer Picture of the Mobility Needs of Older Americans. J Am Plan Assoc 2019; 85 : 482-500. https://doi.org/10.1080/01944363.2019.1630295

25. Jonck JW. Arrive Alive Website. https://www.arrivealive.co.za/contact-us 2020; 086 | 400800.

26. Ramachandran M, Dsouza SA. Older Adults' Experiences of Community Mobility in an Indian Metropolis: A Qualitative Study. Phys Occup Ther Geriatr 2018; 36: 315-329. https://doi.org/10.1080/02 703181.2018 .1508170

27. Njwambe A, Cocks M, Vetter S. Ekhayeni: Rural-Urban Migration, Belonging and Landscapes of Home in South Africa. J South Afr Stud 2019; 45: 4I3-43I. https://doi.org/10.1080/03057070.2019.1631007

28. McAdam JC, Franzsen D, Casteleijn D. Identification of occupations in a South African rural less-resourced community. J Occup Sci 2019; 26: 379-393. https://doi.org/10.1080/14427591.2019.1614476

29. Lilenstein K, Woolard I, Leibbrandt M. In-work poverty in South Africa: the impact of income sharing in the presence of high unemployment. In: Lohmann H, Marx I (eds) Hanbook on In-work Poverty. Cheltenham, UK: Edward Elgar Publishing, 2018, p. 528. https://doi.org/10.4337/978I7847/5632.00032

30. South African Government. Old Age Pension. Older Person's Grant. South African Social Security Agency 2021; www.gov.za.

31. Mupedziswa R, Rankopo M, Mwansa L. Ubuntu as a Pan-African Philosophical Framework for Social Work in Africa. Kampala: Fountain Publishers, 2020.

32. Klopp JM, Paller JW. Slum Politics in Africa. Epub ahead of print 2019. DOI: https://doi.org/I0.1093/acrefore/9780190228637.013.985.

33. Mashiri M, Njenga P, Njenga C, et al. Towards a Framework for Measuring Spatial Planning Outcomes in South Africa. Sociol Anthropol 2017; 5: 146-168. https://doi.org/10.13189/sa.2017.050205

34. Senoa E. Basic Income Support. A case for South Africa. Mowbray, 2020.

35. Ramaphosa C. SONA 202I. State of the Nation Address. Durban, 2021 .

Corresponding Author

*Hester van Biljon

Email: HesterMvanBiljon@gmail.com 